\title{
QTe-Prolonging Drugs and Hospitalizations for Cardiac Arrhythmias
}

\author{
Marie L. De Bruin, PharmD, Arno W. Hoes, MD, PhD, and \\ Hubert G.M. Leufkens, PharmD, PhD
}

Cardiac arrhythmia as an adverse effect of noncardiac drugs has been an issue of growing importance during the past few years. In this population-based study, we evaluated the risk for serious cardiac arrhythmias during the use of several noncardiac QTc-prolonging drugs in day-to-day practice, and subsequently focused on several specific groups of patients who could be extremely vulnerable for drug-induced arrhythmias. We performed a case-control study in which patients (cases), hospitalized for nonatrial cardiac arrhythmias from 1987 to 1998, were compared with their matched controls regarding current use of QTc-prolonging drugs. Odds ratios (OR) and $95 \%$ confidence intervals $(\mathrm{Cl})$ were calculated using multivariate conditional logistic regression, adjusting for potential confounding factors. Data were obtained from the PHARMO record linkage system. We identified 501 cases, 39 of whom used QTc-

ardiac arrhythmias as an adverse effect of noncardiac drugs has been an issue of growing importance in medical science during the last few years, resulting in regulatory action concerning several drugs. ${ }^{1}$ Because of the seriousness of this adverse effect, regulatory action has sometimes already been taken after a few case reports, before the actual risk has been quantified in large population-based studies. For only a few of all QTc-prolonging drugs, studies have unequivocally shown a causal relation between the use of the drugs and the occurrence of cardiac arrhythmias. The use of antihistamines has been associated with an increased risk for cardiac arrhythmias. ${ }^{2}$ In contrast, no increased risk for serious rhythm disorders was observed in patients who took cisapride, ${ }^{3}$ although its use has been linked to the occurrence of cardiac arrhythmias in several case reports. ${ }^{4,5}$ In this population-based study, we evaluated the risk for serious cardiac arrhythmias and the use of several noncardiac QTc-prolonging drugs in day-to-day practice. Subsequently, we focused on several specific groups of patients who may be quite vulnerable to druginduced arrhythmias.

\footnotetext{
From the Utrecht Institute for Pharmaceutical Sciences, Department of Pharmacoepidemiology and Pharmacotherapy; and the Julius Center for Health Sciences and Primary Care, University Medical Center, Utrecht, The Netherlands. Manuscript received May 9, 2002; revised manuscript received and accepted August 12, 2002.

Address for reprints: Marie L. De Bruin, PhD, Utrecht Institute for Pharmaceutical Sciences, Department of Pharmacoepidemiology and Pharmacotherapy, PO Box 80082, 3508 TB Utrecht, The Netherlands. E-mail: m.I.debruin@pharm.uu.nl.
}

prolonging drugs. A statistically nonsignificant increased risk for arrhythmias (OR $1.2,95 \% \mathrm{Cl} 0.8$ to 1.9 ) was observed in patients who received QTc-prolonging drugs. A clearly increased risk of arrhythmias was, however, found in patients with a history of asthma (OR 9.9, $95 \% \mathrm{Cl} 1.0$ to 100$)$ and in patients using potassiumlowering drugs (OR 5.3, 95\% Cl 1.1 to. 25.9). Our data do not suggest that there is a strong overall association between the use of QTc-prolonging drugs and hospitalization for cardiac arrhythmias in the population at large. However, there appears to be clinically relevant associations of patients with a history of asthma and patients taking potassium-lowering drugs. The use of QTc-prolonging drugs should therefore be either avoided or monitored closely in these specific patients. $\subset 2003$ by Excerpta Medica, Inc.

(Am J Cardiol 2003;91:59-62)

\section{METHODS}

Setting: Data were obtained from the PHARMO record linkage system (Utrecht, The Netherlands), which contains drug-dispensing records from community pharmacies and linked hospital discharge records of a defined population of approximately 330,000 residents of 8 medium-sized cities in The Netherlands.

The computerized drug-dispensing histories contained data on the type and quantity of the dispensed drug, type of prescriber, dispensing date, and prescribed dose and daily regimens. Drugs were coded according to the Anatomical Therapeutic Chemical Classification. Hospital discharge records were coded according to the International Classification of Diseases, 9th revision, clinical modification.

Design: We conducted a case-control study in which patients were compared with their matched controls regarding current exposure to QTc-prolonging drugs. Cases were defined as patients hospitalized for nonatrial cardiac arrhythmias (ventricular or nonspecified) for the first time from 1987 to 1998 (Table 1). We only used primary hospital discharge records to exclude patients with noniatrogenic conditions, which may have been caused by myocardial infarction or heart failure. Controls were sampled from all noncases present in the PHARMO cohort at the hospitalization date of the corresponding case (index date). Controls were matched for age (5-year bands), gender, and practice area in a 1:4 ratio. Cases as well as controls had to be in the PHARMO population at least 1 year before the index date.

Exposure definition: Current exposure to QTc-prolonging drugs was investigated. These included non- 
TABLE 1 Number of Various Hospitalizations for Ventricular and Nonspecified Cardiac Arrhythmias in PHARMO 1987 to 1998

\begin{tabular}{|llr|}
\hline ICD Code & \multicolumn{1}{c|}{ Arrhythmia } & $\mathrm{n}$ \\
\hline 427.1 & Paroxysmal ventricular tachycardia & $90(18.0 \%)$ \\
427.2 & Paroxysmal tachycardia, unspecified & $6(1.2 \%)$ \\
427.41 & Ventricular fibrillation & $46(9.2 \%)$ \\
427.42 & Ventricular flutter & $1(0.2 \%)$ \\
427.5 & Cardiac arrest & $22(4.4 \%)$ \\
427.60 & Premature beats, unspecified & $2(0.4 \%)$ \\
427.69 & Other (ventricular) premature beats & $19(3.8 \%)$ \\
427.89 & Other specified cardiac dysrhythmias & $199(39.7 \%)$ \\
427.9 & Cardiac dysrhythmia, unspecified & $116(23.2 \%)$ \\
\multicolumn{3}{|l}{ Total } \\
\hline \multicolumn{3}{|l}{ ICD = International Classification of Diseases, 9th edition. } \\
\hline
\end{tabular}

\begin{tabular}{|lcc|}
\hline \multicolumn{2}{|l|}{ TABLE 2 Main Characteristics of Patients Hospitalized for Cardiac Arrhythmias } \\
(cases) and Their Matched Controls
\end{tabular}

comitant use of these inhibitors increases blood plasma levels. The multiplication factor was an average of increases in maximum plasma concentrations found in pharmacokinetic studies. ${ }^{9,19,20}$ Duration of use was only calculated for chronic therapies (excluding antihistamines and antibiotics) as days of use since first prescription. If $>1$ QTc-prolonging drug was used at the index date, individual doses were added and the shortest duration of use was taken.

Potential confounders: The association between the use of QTc-prolonging drugs and hospitalization for cardiac arrhythmias in this population-based study may be confounded by secondary factors that were associated with both the exposure and the outcome, such as confounding by indication. ${ }^{21}$ We therefore adjusted the calculated associations for concomitant use of drugs that can lower blood potassium levels (nonpotassium-sparing diuretics, ${ }^{22}$ laxatives, ${ }^{23,24}$ corticosteroids for systemic use, ${ }^{25}$ and systemic $\beta_{2}$ agonists ${ }^{25,26}$ ). We also adjusted calculated associations for current treatment for arrhythmias, number of hospitalizations in the year before the index date, and history of cardiac disease, asthma, ${ }^{27}$ and diabetes mellitus. ${ }^{28}$ To control for the last 3 factors, proxies obtained from our data were used- $\geq 2$ previous prescriptions for cardiac, antidiabetic, or asthma/chronic obstructive pulmonary disease drugs, and/or previous hospitalization for ischemic heart disease, heart failure, coronary artery bypass graft surgery, and percutaneous transluminal coronary angioplasty, and diabetic causes or asthma.

Effect modification: The risk for hospitalization for drug-induced arrhythmias may differ among several subpopulations of our study population. We investigated whether the risk differed between gender, age groups ( \pm 65 years) and patients with and without several diseases (asthma, diabetes mellitus, cardiac disease) or possible interfering medications (potassium-lowering drugs, antiarrhythmic drugs)

Data analysis: Odds ratios (ORs) and 95\% confidence intervals (CIs) were calculated using conditional logistic regression. All statistical analyses were performed using SPSS 10.0 (SPSS Inc., Chicago, Illinois).

\section{RESULTS}

During the study period of 1987 to 1998 , a total of 501 cases of ventricular or nonspecified cardiac arrhythmia were identified in the study population. This corresponds to an incidence of about 16 new cases per 100,000 inhabitants per year. The most commonly reported arrhythmia was "other specified cardiac dysrhythmias," followed by "cardiac dysrhythmia, unspecified" and "paroxysmal ventricular tachycardia" (see Table 1).

About $57 \%$ of the cases were men (mean age 


\begin{tabular}{|c|c|c|}
\hline & $\begin{array}{c}\text { Cases } \\
(\mathrm{n}=501)\end{array}$ & $\begin{array}{c}\text { Controls } \\
(\mathrm{n}=2,204)\end{array}$ \\
\hline Second generation antihistamines & $3(0.6 \%)$ & $20(1.0 \%)$ \\
\hline Classical antipsychotics & $6(1.2 \%)$ & $20(1.0 \%)$ \\
\hline Atypical antipsychotics & $1(0.2 \%)$ & $1(<0.1 \%)$ \\
\hline Tri- or tetracyclic antidepressives & $8(1.6 \%)$ & $37(1.8 \%)$ \\
\hline Cisapride & $3(0.6 \%)$ & $8(0.4 \%)$ \\
\hline Fluoroquinolones* & 5 (1.0\%) & $4(0.2 \%)$ \\
\hline Cotrimoxazole & $2(0.4 \%)$ & $8(0.4 \%)$ \\
\hline Glibenclamide & $13(2.6 \%)$ & $29(1.4 \%)$ \\
\hline Any QTc-prolonging drug ${ }^{\dagger}$ & $39(7.8 \%)$ & $120(6.0 \%)$ \\
\hline \multicolumn{3}{|c|}{$\begin{array}{l}\text { *Statistically significant difference at } \alpha=0.05 \text {. } \\
\text { †Some patients used }>1 \text { QTc-prolonging drug: therefore, numbers do no } \\
\text { add up. }\end{array}$} \\
\hline
\end{tabular}

approximately 65 years). Thirty-nine patients (7.8\%) were on a QTc-prolonging drug on the index date compared with $6.0 \%$ of the controls. Two patients and 3 controls were also receiving drugs that inhibited cytochrome P-450 metabolism.

Characteristics of the cases and controls are listed in Tables 2 and 3. Compared with controls, more patients had a history of cardiac disease, were hospitalized in the year before the index date, and took antiarrhythmic medication or drugs that could lower blood potassium levels at the index date.

Compared with nonusers, patients who were using QTc-prolonging drugs more often had a history of diabetes $(34 \%$ vs $10 \%)$ or cardiac disease $(40 \%$ vs $31 \%$ ), were hospitalized more often in the year before the index date (26\% vs $16 \%$ ), and took potassiumlowering drugs more often ( $24 \%$ vs $17 \%$ ). These patients were also significantly older than the nonusers (69 vs 65 years, respectively).

Current use of any QTc-prolonging drug was not statistically significantly associated with an increased risk of hospitalization for cardiac arrhythmias. This estimate did not change after adjustment for potential confounding factors (adjusted OR 1.2, 95\% CI 0.8 to 1.9). Patients taking higher dosages ( $>1$ defined daily dose) appeared to be slightly more at risk than patients taking lower dosages ( $\leq 1$ defined daily dose) compared with nonusers (adjusted OR 1.4, 95\% CI 0.6 to 3.2 vs OR $1.2,95 \%$ CI 0.7 to 1.9). Also, the risk for drug-induced arrhythmias appeared to occur within the first 2 months of use (adjusted OR 3.4, 95\% CI 1.1 to 10.3). The risk in patients taking their long-term medication for $>2$ months was 1.0 (95\% CI 0.6 to 1.7). When looking at individual drug classes, the association between use and hospitalization for cardiac arrhythmias was most pronounced for fluoroquinolones (adjusted OR 4.2, 95\% CI 1.0 to 17.7). The $95 \%$ confidence limits of this estimate, however, are relatively wide.

Of the subgroups of patients studied, those with a history of asthma (adjusted OR 9.9, 95\% CI 1.0 to $100)$ and those taking potassium-lowering drugs (adjusted OR 5.3, 95\% CI 1.1 to 25.9) were most prone to develop cardiac arrhythmias while on QTc-prolonging
TABLE 4 Adjusted Odds Ratios (OR) and 95\% Confidence Intervals (CI) of Cardiac Arrhythmias in Subgroups of Users of QTc-prolonging Drugs

\begin{tabular}{|lcc|}
\hline Subgroup & OR & $95 \% \mathrm{Cl}$ \\
\hline Overall & 1.2 & $0.8-1.9$ \\
Men & 1.1 & $0.6-2.0$ \\
Women & 1.4 & $0.8-2.7$ \\
Age $<65$ yrs & 0.7 & $0.3-1.8$ \\
Age $\geq 65$ yrs & 1.6 & $1.0-2.6$ \\
History of diabetes mellitus & 1.1 & $0.1-9.5$ \\
No history of diabetes mellitus & 1.2 & $0.7-2.1$ \\
History of asthma & 9.9 & $1.0-100$ \\
No history of asthma & 1.0 & $0.6-1.6$ \\
History of cardiac disease & 1.5 & $0.8-2.9$ \\
No history of cardiac disease & $-{ }^{*}$ & \\
Current use of any potassium-lowering & 5.3 & $1.1-25.9$ \\
$\quad$ drug & 1.3 & $0.8-2.1$ \\
No current use of potassium-lowering & & \\
drugs & 1.7 & $0.2-13.6$ \\
Current use of antiarrhythmic drugs & 1.3 & $0.8-2.3$ \\
\hline No current use of antiarrhythmic drugs & & \\
\hline *Not possible to calculate because of lack of power. & \\
\hline
\end{tabular}

drugs. Results of the logistic regression are listed in Table 4.

\section{DISCUSSION}

Our findings do not support the hypothesis that the use of QTc-prolonging drugs results in increased hospitalization rates for cardiac arrhythmias (OR 1.2, $95 \%$ CI 0.8 to 1.9 ). This may be because the clinical impact of the use of these drugs is not very high in the general population or that in day-to-day practice the drugs are avoided in high-risk groups.

Our findings indicate that patients with a history of asthma or those taking potassium-lowering drugs are most prone to develop cardiac arrhythmias.

Cardiac arrhythmias that require hospitalization are not the only type of clinically relevant arrhythmia that can result from drug use. When drug-induced QTc prolongation results in sudden death, ${ }^{6}$ patients will not be admitted to the hospital. Therefore, the cases we studied are not representative of all relevant arrhythmias that may have occurred. Because it is very difficult to identify fatal arrhythmia cases outside the hospital, we were unable to address this issue. We believe, however, that an increased risk of arrhythmias leading to hospital admissions will also manifest itself in an increased risk of sudden death.

Another factor that may have influenced our results is the fact that we were not able to verify whether all cases were real cases of ventricular arrhythmias. Until the present time, we were unable to review the electrocardiographic evidence for the different arrhythmias. However, we excluded all cases of atrial arrhythmias from our analyses, and when restricting the analysis to only the proved ventricular arrhythmias, comparable results were found despite loss of power.

In our study, we used drug-dispensing records from community pharmacies. Patients who picked up their medication, however, might not have actually taken the prescribed drugs. This possible lack of com- 
pliance may have overestimated the actual exposure, and thus biased our results toward the null hypothesis.

The increased risk in patients taking potassiumlowering drugs can be explained by the fact that low extracellular potassium reduces the delayed rectifier potassium ion current $\left(\mathrm{I}_{\mathrm{Kr}}\right),{ }^{29}$ which is also blocked by QTc-prolonging drugs. Drugs reducing blood potassium included non-potassium-sparing diuretics, laxatives, corticosteroids for systemic use, and systemic $\beta_{2}$ agonists. Diuretics are used for lowering blood pressure. Patients taking these drugs may have other cardiac diseases that cause the higher risk for druginduced arrhythmias. A similar bias may have occurred with patients using systemic $\beta_{2}$ agonists for treating asthma. Asthma, and not the reduction in blood potassium, may have caused the increased risk we found. 26,30

1. Haverkamp W, Breithardt G, Camm AJ, Janse MJ, Rosen MR, Antzelevitch C, Escande D, Franz M, Malik M, Moss A, Shah R. The potential for QT prolongation and pro-arrhythmia by non-anti-arrhythmic drugs: clinical and regulatory implications. Report on a Policy Conference of the European Society of Cardiology. Cardiovasc Res 2000;47:219-233.

2. de Abajo FJ, Rodriguez LA. Risk of ventricular arrhythmias associated with nonsedating antihistamine drugs. Br J Clin Pharmacol 1999;47:307-313.

3. Walker AM, Szneke P, Weatherby LB, Dicker LW, Lanza LL, Loughlin JE, Yee CL, Dreyer NA. The risk of serious cardiac arrhythmias among cisapride users in the United Kingdom and Canada. Am J Med 1999;107:356-362.

4. Wysowski DK, Bacsanyi J. Cisapride and fatal arrhythmia. N Engl J Med 1996;335:290-291

5. Bran S, Murray WA, Hirsch IB, Palmer JP. Long QT syndrome during high-dose cisapride. Arch Intern Med 1995;155:765-768.

6. Glassman AH, Bigger JT Jr. Antipsychotic drugs: prolonged QTc interval, Torsades de Pointes, and sudden death. Am J Psychiatry 2001;158:1774-1782. 7. Burckhardt D, Raeder E, Muller V, Imhof P, Neubauer H. Cardiovascular effects of tricyclic and tetracyclic antidepressants. JAMA 1978;239:213-216.

8. Zehender M, Meinertz T, Hohnloser S, Geibel A, Hartung J, Seiler KU, Just $\mathrm{H}$. Incidence and clinical relevance of QT prolongation caused by the new selective serotonin antagonist ketanserin. Multicenter Ketanserin Research Group. Clin Physiol Biochem 1990;8:90-100.

9. van Haarst AD, van't Klooster GA, van Gerven JM, Schoemaker RC, van Oene JC, Burggraaf J, Coene MC, Cohen AF. The influence of cisapride and clarithromycin on QT intervals in healthy volunteers. Clin Pharmacol Ther 1998;64:542546.

10. Matson PA, Luby SP, Redd SC, Rolka HR, Meriwether RA. Cardiac effects of standard-dose halofantrine therapy. Am J Trop Med Hyg 1996;54:229-231.

11. Eisenhauer MD, Eliasson AH, Taylor AJ, Coyne PE Jr, Wortham DC.
Incidence of cardiac arrhythmias during intravenous pentamidine therapy in HIV-infected patients. Chest 1994;105:389-395.

12. Brandriss MW, Richardson WS, Barold SS. Erythromycin-induced QT prolongation and polymorphic ventricular tachycardia (Torsades de Pointes): case report and review. Clin Infect Dis 1994;18:995-998.

13. Lee KL, Jim MH, Tang SC, Tai YT. QT prolongation and Torsades de Pointes associated with clarithromycin. Am J Med 1998;104:395-396.

14. Ball P. Quinolone-induced QT interval prolongation: a not-so-unexpected class effect. J Antimicrob Chemother 2000;45:557-559.

15. Lopez JA, Harold JG, Rosenthal MC, Oseran DS, Schapira JN, Peter T. QT prolongation and torsades de pointes after administration of trimethoprim-sulfamethoxazole. Am J Cardiol 1987;59:376-377.

16. Rosati B, Rocchetti M, Zaza A, Wanke E. Sulfonylureas blockade of neural and cardiac HERG channels. FEBS Lett 1998;440:125-130.

17. Gohn DC, Simmons TW. Polymorphic ventricular tachycardia (Torsades de Pointes) associated with the use of probucol. N Engl J Med 1992;326:1435-1436. 18. Henderson RA, Lane S, Henry JA. Life-threatening ventricular arrhythmia (Torsades de Pointes) after haloperidol overdose. Hum Exp Toxicol 1991;10:5962.

19. Abernethy DR, Barbey JT, Franc J, Brown KS, Feirrera I, Ford N, Salazar DE. Loratadine and terfenadine interaction with nefazodone: both antihistamines are associated with QTc prolongation. Clin Pharmacol Ther 2001;69:96-103. 20. Desta Z, Kerbusch T, Flockhart DA. Effect of clarithromycin on the pharmacokinetics and pharmacodynamics of pimozide in healthy poor and extensive metabolizers of cytochrome P450 2D6 (CYP2D6). Clin Pharmacol Ther 1999; $65: 10-20$.

21. Collet JP, Boivin JF. Bias and confounding in pharmacoepidemiology. In: Strom BL, ed. Pharmacoepidemiology. Chichester: John Wiley Ltd, 2000:765784.

22. Grobbee DE, Hoes AW. Non-potassium-sparing diuretics and risk of sudden cardiac death. J Hypertens 1995;13:1539-1545.

23. Chin RL. Laxative-induced hypokalemia. Ann Emerg Med 1998;32:517-518. 24. Yelamanchi VP, Molnar J, Ranade V, Somberg JC. Influence of electrolyte abnormalities on interlead variability of ventricular repolarization times in 12lead electrocardiography. Am J Ther 2001;8:117-122.

25. Taylor DR, Wilkins GT, Herbison GP, Flannery EM. Interaction between corticosteroid and beta-agonist drugs. Biochemical and cardiovascular effects in normal subjects. Chest 1992;102:519-524.

26. Bouvy ML, Heerdink ER, De Bruin ML, Herings RM, Leufkens HG, Hoes AW. Use of sympathomimetic drugs leads to increased risk of hospitalization for arrhythmias in patients with congestive heart failure. Arch Intern Med 2000;160: 2477-2480.

27. Rosero SZ, Zareba W, Moss AJ, Robinson JL, Hajj Ali RH, Locati EH, Benhorin J, Andrews ML. Asthma and the risk of cardiac events in the Long QT syndrome. Long QT Syndrome Investigative Group. Am J Cardiol 1999;84: 1406-1411.

28. Arildsen H, May O, Christiansen EH, Damsgaard EM. Increased QT dispersion in patients with insulin-dependent diabetes mellitus. Int J Cardiol 1999;71: 235-242.

29. Yang T, Roden DM. Extracellular potassium modulation of drug block of IKr. Implications for Torsades de Pointes and reverse use-dependence. Circulation 1996;93:407-411.

30. Williams C. Baseline rates of disease may account for some arrhythmia risk. Arch Intern Med 2001;161:1235-1236. 